ORIGINAL RESEARCH

\title{
Impact of COVID-19 Pandemic on Mental Health of University
}

\section{Students in Pakistan}

Hafiz Muhammad Asif

Hafiz Abdul Sattar Hashmi

University College of Conventional Medicine, Faculty of Medicine \& Allied Health Sciences, The Islamia University of Bahawalpur, Punjab, Pakistan

${ }^{*}$ Correspondence: Dr. Hafiz Muhammad Asif

University College of Conventional Medicine, Faculty of Pharmacy \& Alternative Medicine, The Islamia University of Bahawalpur, Pakistan

Tell: +923346911256

Email: muhammad.asif@iub.edu.pk, doctor.asif101@gmail.com 


\section{Abstract}

Purpose: A novel coronavirus, SARS-CoV-2 was identified as the cause of COVID-19 eventually led to the declaration of Public health emergency of international concern and a pandemic by WHO due to its exponential global spread. Present study was conducted to investigate the impact of second wave of pandemic on mental wellbeing and social behaviors among university students of Pakistan during this crucial period of COVID-19 infection. Methods: A cross-sectional analytical study was designed to evaluate the psychosocial impact during the current COVID-19 outbreak among the students of The Islamia University of Bahawalpur, Pakistan. Snowball sampling or chain referral sampling procedure was adopted to recruit the participants in the study. Verbal informed consent was taken from all participants before recruitment in the study irrespective of their gender, age and socioeconomic status. Results: Mental health of university students during COVID-19 epidemic was affected to a varying degree revealing that $26.66 \%$ were recorded to have mild, $27.15 \%$ moderate and $17.04 \%$ suffering from severe anxiety out of total 1029 students. Students who were residing in urban areas with parents and having a steady family income were negatively associated and found protective factors against anxiety. However, having a relative or an acquaintance infected with COVID-19 was an independent risk factor for experienced anxiety. Positively associated factors with the level of anxiety symptoms included economic stressors, effects on daily-life, and academic delays whereas social support was negatively correlated with anxiety in COVID-19 related stressors. Conclusion: Public health emergencies and such pandemic are exerting serious psychological impacts on university students. It is recommended that the higher authorities should plan better policies to reduce this impact for the provision of high quality and timely crisis-oriented psychological services to university students.

Key Words: Psychosocial impact; anxiety; Covid-19 stressors; policies; public health emergencies; pandemics

\section{Introduction}

Coronavirus family has caused 3 epidemics (SARS-2003, MERS-2012, and COVID-2019) over the past few decades affecting large number of people globally. ${ }^{1}$ Earlier epidemic was reported on December 12, 2019 epidemiologically associated with a seafood market of Wuhan, Hubei Province of China when some cases of pneumonia of unknown etiology were reported. ${ }^{2}$ The clinical manifestation of 
most of the patients was dry cough, dyspnea, and fever. Zoonotic to human and then human to human transmissions of pathogens were reported in all thrice outbreaks. Since then, the quantity of cases increased rapidly inside and outside Wuhan, occupying to 34 cities of China by 30 January $2020 .^{3}$

It was named as coronavirus disease 2019 (COVID-19) after the identification of a novel coronavirus, SARS-CoV-2 as the cause of this pandemic in China and other parts of the world. Eventually, WHO declare Public health emergency of international concern on January 30, 2020 and a pandemic on March 11, 2020 due to its exponential global spread. ${ }^{4}$ The COVID-19 appeared to be more contagious due to its diverse epidemiological and biological characteristics than earlier pandemics such as SARS-2003, MERS-2012. ${ }^{5}$ It has affected more than 200 countries globally with $70,461,926$ total cases and 1,599,704 deaths as of December 14, 2020. ${ }^{6}$ Case-fatality rate (CFR) among confirmed cases of COVID-19 is estimated at $6.80 \%$, despite its significant infectivity rate. Majority of the deaths are typically occurring among the patients above 80 years of age, having multiple comorbidities and the immunocompromised population. ${ }^{7}$

In Pakistan, after a brief hiatus of following the first case which was reported on February 26, 2020, Covid-19 cases spiked as more pilgrims returned from Iran and a large number of members of Tableeghi Jamaat, a religious congregation were also tested covid-19 positive, affected more than 438,425 persons and 8,796 deaths till December 14, 2020.Covid-19 epidemic in Pakistan posed a serious challenge to counter it with limited resources of country. 8,9

Covid-19 pandemic led to closure of all educational institutions globally and thus giving rise to multiple challenges at all stages and levels of education in particular for students. ${ }^{10}$ Higher education commission (HEC), Pakistan, institutional administrators, teachers, students, and other stakeholders are making considerable efforts and planning to optimally utilize the available technology for continuing the process of education and minimizing the gaps that are ongoing in consequent of the current pandemic of COVID-19. ${ }^{11}$

Psychological distress is strongly associated with widespread outbreaks of infectious disease, such as COVID-19 and symptoms of mental illness appeared in general population. ${ }^{12}$ The current global pandemic also has consequences for mental health, as happened in some previous health emergencies. ${ }^{13}$ These manifestations should be addressed by psychiatrists across the world, their 
correlates, and strategies to manage them that counter both the needs of specific populations and the precautionary measures essential to limit the spread of COVID-19. ${ }^{14}$

There are several studies on the psychological impact of the Covid-19 epidemic on the patients, medical professionals, general public, children,and older adults in Pakistan as well as all over the world. ${ }^{15,16}$ However, no detailed investigation on the psychological impact and mental health status of university students bearing the epidemic has been conducted till now. The aim of the present study was to investigate the impact of current pandemic on mental wellbeing and social behaviors among university students during this crucial period of COVID-19 infection.

\section{Material and Methods}

\section{Participants and Setting}

A cross-sectional analytical study was designed to evaluate the psychosocial impact during the current COVID-19 outbreak among the students of The Islamia University of Bahawalpur, Pakistan. A snowball sampling or chain referral sampling procedure was adopted to recruit the participants in the study. Students who gave verbal informed consent were recruited in the study irrespective of their gender, age and socioeconomic status. The pre-COVID-19 period was defined as from December 2019 until February 20202 while post-COVID-19 period was defined from March 2020 until June 2020. Ethical approval was obtained from the Departmental Research Committee (DRC) (UCCM-DRC-003-2020, Dated April 15, 2020). All the standards of Declaration of Helsinki were followed strictly to execute the study on Human subjects.

\section{Data Collection and Procedure of Study}

Students were invited by using electronic and social media resources as the Government of Pakistan suspends all kind of social gathering, public meetings, transport and travelling to minimize direct personal interactions and instruct to stay at home. All the participants were informed about this study through University website, dedicated social media resources etc. Data was collected over 30 days (November 11, 2020- December 10, 2020) during the exponential phase of COVID-19 in Pakistan under the strict enforcement of lockdown. Undergraduate \& graduate students belonging to health \& medicine 
disciplines, enrolled in University College of Conventional Medicine, The Islamia University of Bahawalpur, Pakistan were recruited initially and they were encouraged to disseminate the information to others for the collection of data. Mental health status was assessed by structuring an anonymous online questionnaire ensuring the confidentiality and reliability of the data of all respondents. All the respondents were considered eligible who provided consent, complete information, and followed the directions to a validity item.

\section{Generalized Anxiety Disorder Scale (GAD-7)}

The online questionnaire (Google online doc/form) was designed comprising of basic demographic characteristics such as name, gender, age, parental occupation and economic status/monthly income, religion, and contact information. Personal information of the entire participants including names and contact details were anonymized to maintain and protect confidentiality. Cognitions and preventive behavior towards COVID-19 and the availability of social support was also inquired.

The participants responded to the 7-item Generalized Anxiety Disorder Scale (GAD-7) which includes seven core symptoms, i. Feeling nervous, anxious, or on edge; ii. Not being able to stop or control worrying; iii. Worrying too much about different things; iv. Trouble relaxing; v. Being so restless that it's hard to sit still; vi. Becoming easily annoyed or irritable; vii.Feeling afraid as if something awful might happen.

Respondents report their symptoms using a 4-item Likert rating scale ranging from 0 (not at all sure), 1 (Several days), 2 (Over half the days), 3 (Nearly every day). The GAD-7 is a valid and reliable tools for the assessment of psychological impact and mental health among society during these circumstances (Cronbach's a $=0.911) .{ }^{17}$

\section{Data analysis}

Demographic and other selected characteristics of the respondents were analyzed by descriptive statistics. A univariate analysis (Nonparametric test) was used to reveal the significant associations between anxiety level and characteristics of sample. ${ }^{18}$ Statistically significant variables were screened and included in multivariate logistic regression analyses. Odds ratio (OR) with $95 \%$ confidence interval (CI) was used to demonstrated the strength of association. Spearman's rank correlation coefficientwas 
used to evaluate the association between COVID-19-related stress factors, suspension or delays in curricular/academic activities, economic and social stressors and anxiety level. A two-tailed $p<.05$ was considered statistically significant. All statistical analysis were performed using SPSS Statistic 21.0 (IBM SPSS Statistics, Chicago, IL, United States).

\section{Results}

\section{Baseline characteristics of Participants}

The online questionnaire was filled by 1045 participants out of 1500 invited individual. The response rate was calculated as $69.66 \%$. The remaining individuals who were not willing to participate in the study $(n=455)$ provided no valid reason. Out of 1045 respondents, $16(1.53 \%)$ individuals did not completely fill the questionnaire and eventually excluded from the final calculations. So, there were total 1029 respondents, 544 (52.86\%) were male and 485 (46.13\%) were female recruited in the study.

\section{Mental Health Status of university students during the}

\section{COVID-19 outbreak}

Mental health of university students during COVID-19 epidemic was affected to a varying degree. No symptoms of anxiety was recorded in $27.45 \%$, while $26.66 \%$ were recorded to have mild, $27.15 \%$ moderate and $17.04 \%$ severe anxiety out of total 1029 students as shown in Figure 1 . The ratio of anxiety and the discipline wise details of students are given in Table 1.

\section{Association of Anxiety with Demographic variables of}

\section{students}

The demographic and selected characteristics of the study population are shown in Table 2. Among the sample of 1029 university students, male were 544 (52.86\%) and female were 485 (47.13\%). Most of the respondents lived in Punjab Province; 603 (58.60\%) lived in rural areas, 721(70.06\%) lived with their parents, and $749(72.78 \%)$ of the parents of students did not have a steady income. Most participants 1017 (98.9\%) had no relatives or acquaintances who were infected with COVID-19. 
Significant association $(P<0.001)$ between severe level of anxiety and female gender $94(19.38 \%)$, students from rural areas 98 (16.25), without a steady income 111(14.81\%) and students not living with parents 32(10.38) was reported. Table 2 shows the detailed relationship between the demographic variables of students and level of anxiety.

\section{Factors associated with anxiety during the COVID-19}

\section{epidemic}

Results of factors associated with anxiety during the COVID-19 crisis are presented in Table 3 by ordinal multivariate analysis. Significance factors from the univariate analysis were included in the ordered logistic regression analysis.

\section{COVID-19-related stress factors and level of anxiety}

Worry about interruption or delay in academic activities $(r=0.217, P<0.001)$, economic influences $(r=0.321, P<0.001)$ and the influence of the epidemic on daily life $(r=0.226, P<0.001)$ were also moderately and positively correlated with the level of anxiety while a negative association between social support and anxiety symptoms during the COVID-19 outbreak was revealed $(r=-0.121, P<0.001)$ as shown in Table 4.

\section{Discussion}

National Action Plan for Corona virus disease (Covid-19) by Government of Pakistan have been enforcedaimed at National effort for response to COVID-2019 emergency in Pakistan while ensuring continual maximum preparedness and optimal and effective response capacity to the current pandemic COVID-2019. Government of Pakistan suspends all the public meetings, transport and travelling to minimize direct personal interactions and instruct to stay at home and complete lockdown in Pakistan was observed on March 12, 2020 for 15 days which is being extended till now as the cases of COVID-19 are rising gradually influencing the psychosocial health of people and economy of country. ${ }^{10}$ These precautionary measures undoubtedly exert some impact on the education and the growth of students. Similar reports have been documented from China revealing that closure of all institutes, social distancing, travel warnings and bans, and extending the national holidays to control the outbreak 
inevitably disrupted routine life and resulted in anxiety. ${ }^{19}$ Some previous reports have also revealed that public health crises can have numerous mental consequences among general population as well as among the college and university students, which can be expressed as anxiety, stress and fear. ${ }^{20}$

We investigated that $26.66 \%$ have mild, $27.15 \%$ moderate and $17.04 \%$ severe anxiety on account of the COVID-19 flare-up. Anxiety in students might be due to the impact of the epidemic on their studies and future work. ${ }^{21}$ Place of residence, source of parental income, whether living with parents and whether a relative or an acquaintance was infected with COVID-19 is strongly associated with level of anxiety. High level of anxiety was recorded among the students residing in rural areas as compared to urban areas which might be due to better health and education resources in cities. Living with parents was another favorable factor against feeling anxious. Previous studies have indicated that the risk factors associated with emotional and anxiety disorders in adults include the death of parents in childhood, not living with parents, and parents' psychological problems and mental illnesses, which are consistent with the results of this study. ${ }^{22,23}$

The COVID-19-related stressors, which include economic stressors, effects on daily life, and academic delays, were positively associated with anxiety symptoms during the epidemic. E-learning methods of teaching are being recommended by higher authorities in Pakistan to reduce the academic loss of students. Despite the world wide adoption of e-learning, it was never considered as a part of formal education in Pakistan by many institutions until the spread of Covid-19. However, in spite of its multiple advantages there are quite a few limitations of e-learning such as social isolation, lack of student teacher interaction and connectivity issues etc. ${ }^{24,25}$ This sudden interruption of academic activities might have led to stress and anxiety and negative psychological impact among students.

Significant impact on the economy of the country and on the life of individuals in addition to the national health crises due to these epidemics have recorded in similar studies. ${ }^{26}$ Lose of source of income lead to anxious feeling about paying their tuition fees. ${ }^{27}$ This result suggests that effective and robust social support is necessary during public health emergencies. ${ }^{28}$ Many appreciable measures were taken by the Government of Pakistan to help the poor populace of the country which includes Rs1.13 trillion (\$7 billion) stimulus package to offer relief to the economy and people during COVID-19 announced by federal 
government. One of the biggest reliefs was Ehsaas Emergency Cash programme offering one-time cash assistance of Rs. 12,000 each to support 12 million families. ${ }^{10}$

Specific strategies providing mental health services in an easily accessible manner should be developed to minimize the impact of these health emergencies. These includes online surveys to assess the scope of mental health problems; mental health education by developing online materials; online counselling and self-help services material; telepsychiatry consultation by developing structured letters; telemedicine services for diagnostic and counselling purposes; online mental health services are needed which should be easily accessible to lower socioeconomic society. ${ }^{29,30}$

\section{Limitations and Strengths}

Our study has several limitations. We adopted snowball sampling or chain referral sampling procedure due to current conditions, limited resources and time-sensitivity of the COVID-19 epidemic rather random selection of the sample. Furthermore, this study is limited to the students who had internet resources, smartphones, whatsapp and e-mail IDs. This study conducted among university students those represents the educated population of the country, so it should not be generalized to the whole population. The level of anxiety and stressor factors in uneducated population may be varied from the results. Despite these limitations, our study presents vital data regarding the psychological impact of COVID-19 outbreak and provides health authorities and researchers a brief mental health status to assist their efforts and policies to fight against negative psychological impact of COVID-19 epidemic in vulnerable groups.

\section{Conclusion}

Mental health of university students during COVID-19 epidemic was affected to a varying degree revealing that $26.66 \%$ were recorded to have mild, $27.15 \%$ moderate and $17.04 \%$ severe anxiety out of total 1029 students. Students who were residing in urban areas with parents and having a steady family income were negatively associated and found protective factors against anxiety. However, having a relative or an acquaintance infected with COVID-19 was an independent risk factor for experienced anxiety. Positively associated factors with the level of anxiety symptoms included economic stressors, effects on daily-life, and academic delays whereas social support was negatively correlated with anxiety 
in COVID-19 related stressors. Public health emergencies and such pandemic are exerting some serious psychological impacts on university students. It is recommended that the higher authorities should plan better policies to reduce this impact for the provision of high quality and timely crisis-oriented psychological services to university students.

\section{Acknowledgment}

Authors are thankful to the students and administration of University College of Conventional Medicine, The Islamia University of Bahawalpur for their support in the collection of data. Authors are thankful to public relation office of the Islamia University of Bahawalpur for providing support in disseminating the information on university website and social media groups for the purpose of collection of data.

\section{Funding}

This research did not receive any specific grant from funding agencies in the public, commercial, or notfor-profit sectors.

\section{Disclosure}

Authors declare no conflict of interest.

\section{References}

1. Perlman S. Another Decade, Another Coronavirus. N. Engl. J. Med. 2020; 382, 760-2.

2. Phelan AL, Katz R, Gostin LO. The Novel Coronavirus Originating in Wuhan, China: Challenges for Global Health Governance. Jama-J. Am. Med. Assoc. 2020; Jan 30. PubMed PMID: 31999307.

3. Wang C. A novel coronavirus outbreak of global health concern. Lancet 2020; 395, 470-473.

4. Nishiura H. The Extent of Transmission of Novel Coronavirus in Wuhan, China, 2020. J. Clin. Med. 2020; 9,330.

5. World Health Organization. Emergencies: Novel Coronavirus 2019. WHO, 2020, Geneva.

6. World Health Organization (WHO) Coronvirus-19 Dashboard available online at https://covid19.who.int/ accessed on December 14, 2020.(Chan JF, Yuan S, Kok KH, et al. A 
familial cluster of pneumonia associated with the 2019 novel coronavirus indicating person-toperson transmission: a study of a family cluster. The Lancet 2020; 395, 514-23.)

7. Chen Y, Liu Q, Guo D. Emerging coronaviruses: genome structure, replication, and pathogenesis. J. Med. Virolo. 2020; 92, 418-423.

8. Ali I. Pakistan confirms first two cases of coronavirus, Govt. says "no need to panic" Dawn News. 2020, February 24,https://www.dawn.com/news/amp/15367 92.

9. COVID-19 live dashboard (Pakistan): National institute of health Islamabad. https://www.nih.org.pk/novel-coranavirus-2019-ncov/. [ accessed on December 14, 2020].

10. Deng SQ, Peng HJ. Characteristics of and public health responses to the coronavirus disease 2019 outbreak in China. J. Clin. Med. 2020; 9, E575.

11. National Institute of Health (NIH). https://www.nih.org.pk/novel-coranavirus-2019-ncov/. [Accessed $5^{\text {th }}$ May 2020].

12. Bao Y, Sun Y, Meng S, Shi J, Lu L. 2019-nCoV epidemic: address mental health care to empower society. Lancet 2020; 395, e37-e38.

13. Li SW, Wang Y, Yang YY, Lei XM, Yang YF. Analysis of influencing factors of anxiety and emotional disorders in children and adolescents during home isolation during the epidemic of novel coronavirus pneumonia. Chinese J. Child Health 2020; 1-9.

14. Yip PSF, Cheung YT, Chau PH, Law YW. The impact of epidemic outbreak: The case of severe acute respiratory syndrome (SARS) and suicide among older adults in Hong Kong. Crisis, 2010; $31,86-92$.

15. Kwok KO, Wong V, Wei VWI, Wong SYS, Tang JW. Novel coronavirus (2019-nCoV) cases in Hong Kong and implications for further spread. The J. Infect. 2020; 20, 30084-0.

16. Chen $\mathrm{Q}$, Liang M, Li Y, et al. Mental health care for medical staff in China during the COVID-19 outbreak. Lancet Psychiat, 2020; 7, e15-e16.

17. Toussaint A, Hüsing $P$, Gumz A, Wingenfeld K, Härter M, Schramm E, Löwe B. Sensitivity to change and minimal clinically important difference of the 7-item generalized anxiety disorder questionnaire (GAD-7). J Affect. Disord. 2020; 265, 395-401. 
18. Abdellatif W, Ding, J, Jalal S. et al. Lack of gender disparity among administrative leaders of Canadian health authorities. J. Women's Health, 2020 (Larchmt).

19. Tang B, Bragazzi NL, Li, Q, Tang S, Xiao Y, Wu J. An updated estimation of the risk of transmission of the novel coronavirus (2019-nCov). Infect. Dis. Model. 2020; 5, 248-255.

20. Mei SL, Yu JX, He BW, Li JY. Psychological investigation of university students in a university in Jilin province. Med. Soc. (Berkeley) 2011; 24, 84-86.

21. Cornine A. Reducing nursing student anxiety in the clinical setting: an integrative review. Nurs. Educ. Perspect. 2020; 10.

22. Woodgate $R L$, Tailor $K$, Tennent $P$, Wener $P$, Altman $G$. The experience of the self in Canadian youth living with anxiety: a qualitative study. PLOS ONE 2020; 15, e0228193.

23. Gentili D, Bardin A, Ros E, et al. Impact of communication measures implemented during a school tuberculosis outbreak on risk perception among parents and school staff, Italy, 2019. Int. J. Environ. Res. Public Health, 2020; 17, E911.

24. Kwary DA, Fauzie S. Students' achievement and opinions on the implementation of e-learning for phonetics and phonology lectures at Airlangga University. Educ. Pesqui. 2018; 44.

25. Maheshwari S, Zheleva B, Rajasekhar V, Batra B. e-Teaching in pediatric cardiology: A paradigm shift. Ann. Pediatr. Cardiol. 2015; 8,10-13.

26. Kernan WD. Health-related impediments to learning among dental and oral surgery students. J. Prev. Interv. Community 2019; 47, 32-44.

27. Peng L, Zhang J, Li M, et al. Negative life events and mental health of chinese medical students: the effect of resilience, personality and social support. Psychiatry Res. 2012; 196, 138-141.

28. Bai YX, Gegan T, Hai H, Liu ZH, Wang WR, Wang ZG. Correlation between psychological changes of the community crowd and the social support in grave public health event. Inner Mongolia Med. J.2005; 37, 295-297.

29. Liu S, Yang L, Zhang C, et al. Online mental health services in China during the COVID-19 outbreak. Lancet Psychiat, 2020; 7, e17-e18. 
30. Xiao C. A novel approach of consultation on 2019 novel coronavirus (COVID-19)- Related psychological and mental problems: structured letter therapy. Psychiatry Investig. 2020; 17, 175176.

Table 1: Discipline wise ratio of anxiety among university students

\begin{tabular}{|c|c|c|c|}
\hline Students & Anxiety level & Number & Ratio (\%) \\
\hline \multirow{4}{*}{$\begin{array}{l}\text { Arts \& Social Sciences } \\
(n=122)\end{array}$} & Normal & 25 & 22.32 \\
\hline & Mild & 39 & 34.82 \\
\hline & Moderate & 41 & 33.60 \\
\hline & Sever & 17 & 15.17 \\
\hline \multirow{4}{*}{$\begin{array}{l}\text { Basic } \quad \& \quad \text { Applied } \\
\text { Sciences, }(n=147)\end{array}$} & Normal & 26 & 17.68 \\
\hline & Mild & 41 & 27.89 \\
\hline & Moderate & 45 & 30.61 \\
\hline & Sever & 35 & 23.80 \\
\hline \multirow{4}{*}{$\begin{array}{l}\text { Medical } \\
\text { Pharmaceutical } \\
\text { Sciences, }(n=434)\end{array}$} & Normal & 176 & 40.55 \\
\hline & Mild & 97 & 22.35 \\
\hline & Moderate & 82 & 18.89 \\
\hline & Sever & 79 & 18.20 \\
\hline \multirow{4}{*}{$\begin{array}{l}\text { Engineering a } \\
\text { Technology, }(n=121)\end{array}$} & Normal & 33 & 27.27 \\
\hline & Mild & 37 & 30.57 \\
\hline & Moderate & 30 & 24.79 \\
\hline & Sever & 21 & 17.35 \\
\hline \multirow{4}{*}{$\begin{array}{l}\text { Islamic Studies and } \\
\text { Languages, }(n=55)\end{array}$} & Normal & 7 & 12.72 \\
\hline & Mild & 11 & 20.00 \\
\hline & Moderate & 21 & 38.18 \\
\hline & Sever & 16 & 29.09 \\
\hline \multirow{4}{*}{$\begin{array}{l}\text { Commerce, Law and } \\
\text { Business Administration } \\
(n=77)\end{array}$} & Normal & 03 & 3.89 \\
\hline & Mild & 22 & 28.57 \\
\hline & Moderate & 40 & 51.94 \\
\hline & Sever & 12 & 15.58 \\
\hline \multirow{4}{*}{$\begin{array}{l}\text { Agricultural Sciences } \\
\text { and Technology, }(n=73)\end{array}$} & Normal & 07 & 11.11 \\
\hline & Mild & 22 & 34.92 \\
\hline & Moderate & 35 & 47.94 \\
\hline & Sever & 09 & 14.28 \\
\hline
\end{tabular}


Table 2: Association of Anxiety with Demographic variables of students

\begin{tabular}{|c|c|c|c|c|c|c|c|}
\hline Variables & $\begin{array}{l}\text { Total } \\
\text { n (\%) }\end{array}$ & $\begin{array}{c}\text { Normal } \\
\text { n (\%) }\end{array}$ & & Anxiety leve & & Statistics & $\begin{array}{c}\mathbf{P} \\
\text { value }\end{array}$ \\
\hline & & & $\begin{array}{l}\text { Mild } \\
\text { n (\%) }\end{array}$ & $\begin{array}{c}\text { Moderate } \\
\text { n (\%) }\end{array}$ & $\begin{array}{c}\text { Severe } \\
\text { n (\%) }\end{array}$ & & \\
\hline Gender & & & & & & $-5.703^{a}$ & $<0.001$ \\
\hline Male & $544(52.86)$ & $\begin{array}{l}196 \\
(36.02)\end{array}$ & $\begin{array}{l}116 \\
(21.32)\end{array}$ & $\begin{array}{l}137 \\
(25.18)\end{array}$ & 95 (17.27) & & \\
\hline Female & 485 (47.13) & $81(16.70)$ & $\begin{array}{l}153 \\
(31.54)\end{array}$ & $\begin{array}{l}157 \\
(32.37)\end{array}$ & 94 (19.38) & & \\
\hline $\begin{array}{l}\text { Place of } \\
\text { Residence }\end{array}$ & & & & & & $28.321^{b}$ & $<0.001$ \\
\hline Urban & $374(36.34)$ & $\begin{array}{l}178 \\
(47.59)\end{array}$ & 74(19.78) & $64(17.11)$ & $58(15.50)$ & & \\
\hline Rural & $603(58.60)$ & $\begin{array}{l}290 \\
(48.09)\end{array}$ & $121(20.06)$ & $94(15.58)$ & 98 (16.25) & & \\
\hline Un-classified & $52(5.05)$ & $24(46.15)$ & $11(21.15)$ & $12(23.07)$ & $5(9.61)$ & & \\
\hline $\begin{array}{l}\text { Steady } \\
\text { Family } \\
\text { Income }\end{array}$ & & & & & & $-4.152^{a}$ & $<0.001$ \\
\hline Yes & $280(27.21)$ & $122(43.57)$ & $74(26.42)$ & $44(15.71)$ & $40(14.28)$ & & \\
\hline No & $749(72.78)$ & $212(28.30)$ & $231(30.84)$ & $195(26.03)$ & $111(14.81)$ & & \\
\hline $\begin{array}{ll}\text { Live with } & \text { warents }\end{array}$ & & & & & & $-3.517^{a}$ & 0.012 \\
\hline Yes & $721(70.06)$ & $\begin{array}{l}342 \\
(47.43)\end{array}$ & 231(32.03) & $\begin{array}{l}176 \\
(24.41)\end{array}$ & $72(9.98)$ & & \\
\hline No & $308(29.93)$ & $99(32.14)$ & $111(36.03)$ & $66(21.42)$ & $32(10.38)$ & & \\
\hline $\begin{array}{l}\text { Relative or } \\
\text { acquaintance } \\
\text { got COVID- } \\
19\end{array}$ & & & & & & $-2.513^{a}$ & $<0.001$ \\
\hline Yes & $12(1.16)$ & $4(0.38)$ & $5(0.48)$ & $2(0.19)$ & $1(0.09)$ & & \\
\hline No & $1017(98.9)$ & $876(86.13)$ & 92(9.04) & $41(4.03)$ & $8(0.78)$ & & \\
\hline
\end{tabular}

${ }^{\mathrm{a}}$ Mann-Whitney test; ${ }^{\mathrm{b}}$ Kruskal-Wallis test. 
Table 3: Factors associated with anxiety during the COVID-19 crisis

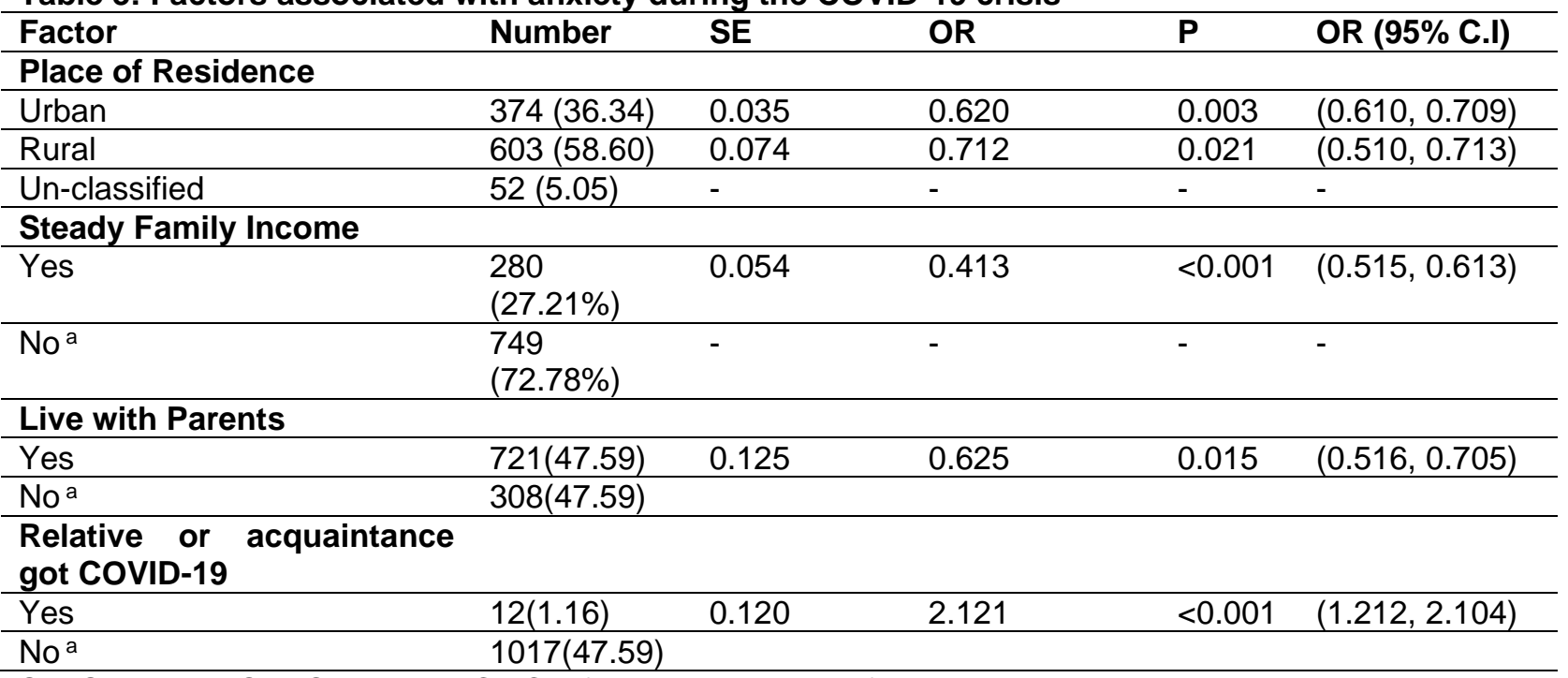

SE: Std. Error, OR: Odds ratio, Cl: Confidence interval, a reference group.

Table 4: COVID-19-related stress factors and level of anxiety

\begin{tabular}{ccc}
\hline Related Stressor & \multicolumn{2}{c}{ Anxiety Level } \\
\hline & $\mathrm{R}$ & $\mathrm{P}$ \\
\hline Worry about academic delays & 0.217 & $<0.001$ \\
\hline Worry about economic influences & 0.321 & $<0.001$ \\
\hline Influence on daily-life & 0.226 & $<0.001$ \\
\hline Social support & -0.121 & $<0.001$ \\
\hline
\end{tabular}

R: Correlation coefficient 


\section{Level of Mental Health}

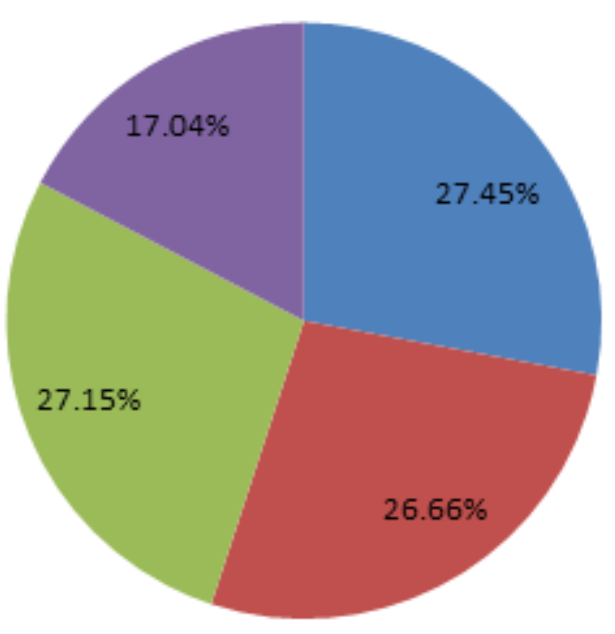

normal

Mild Anxiety

Moderate Anxiety

- Severe Anxiety

Figure 1: Mental Health Status of university students during the COVID-19 outbreak. 